\title{
A Reduced Switch Voltage Stress Class E Power Amplifier Using Harmonic Control Network
}

\author{
Ali Reza Zirak \\ Laser \& Optics Research School, \\ NSTRI, \\ Tehran, Iran
}

\begin{abstract}
In this paper, a harmonic control network (HCN) is presented to reduce the voltage stress (maximum MOSFET voltage) of the class $E$ power amplifier (PA). Effects of the HCN on the amplifier specifications are investigated. The results show that the proposed HCN affects several specifications of the amplifier, such as drain voltage, switch current, output power capability $\left(C_{p}\right.$ factor), and drain impedance. The output power capability of the presented amplifier is also improved, compared with the conventional class $\mathbf{E}$ structure. High-voltage stress limits the design specifications of the desired amplifier. Therefore, several limitations can be removed with the reduced switch voltage. According to the results, the maximum drain voltage for the presented amplifier is reduced and subsequently, the output power capability is increased about $25 \%$ using the presented structure. Zero-voltage switching condition (ZVS) and zerovoltage derivative switching condition (ZVDS) are assumed in the design procedure. These two conditions are essential for high efficiency achievement in various classes of switching amplifiers. A class $E$ PA with operating frequency of $1 \mathrm{MHz}$ is designed and simulated using advanced design system (ADS) and PSpice software. The theory and simulated results are in good agreement.
\end{abstract}

Keywords-class E power amplifier; harmonic control network (HCN); MOSFET drain Impedance; ZVS and ZVDS conditions

\section{INTRODUCTION}

The main blocks in many communication systems are power amplifiers. Power amplifiers are high-consumption elements, and so, their efficiency is an important factor in the design procedure [1-3]. Class $\mathrm{E}$ power amplifiers are very interesting for communication systems due to their high efficiency. Class E amplifiers are also called DC-AC inverters, which are further divided into two main types: the ZVS power amplifiers and the zero current switching (ZCS) power amplifiers. Both ZVS/ZVDS conditions must be considered in the nominal operation of ZVS type amplifiers, while in subnominal operation only ZVS condition is considered. The ZVS type class E PA with nominal operation is studied in this paper. Several researches have been mentioned ZVS and ZVDS conditions as essential conditions to obtain high efficiency in high frequencies [4-6].

Recently, extra parameters have been assumed in some approaches to add one degree of freedom to class E PA design. For example, the shunt intrinsic capacitance $\left(C_{d s}\right)$ of the MOSFET is considered nonlinear, and the grading coefficient is taken into account as a new parameter in class E amplifier

\author{
Sobhan Roshani \\ Department of Electrical Engineering, Kermanshah Branch, \\ Islamic Azad University, \\ Kermanshah, Iran
}

design [7-8]. Besides, input voltage duty cycle is considered to analyse the class E PA in [9-11]. Varying input voltage duty cycle leads to change in the class E PA specifications. Also, recent approaches have introduced several structures with improved MOSFET voltage and current waveforms, such as inverse class E [12-14], class EF [15-17], and class DE power amplifiers [18-19]. Class DE amplifiers are introduced by adding two parallel capacitances to the switching MOSFETs. Class DE amplifiers have high efficiency, but their output power capability $\left(C_{p}\right)$ is low. Inverse structure of class $\mathrm{E}$ is similar to typical structure, but has a dual circuit. ZCS and ZCDS (zero current derivative switching) conditions could be satisfied in Inverse type of class E PA. Combining the structures of class $\mathrm{E}$ and $\mathrm{F}$ PAs leads to class EF family amplifiers. Reduced switch (MOSFET) voltage or current could be achieved in this kind of amplifiers, according to the harmonics effects on the MOSFET voltage and current, while their efficiency is low, compared with the other switching classes. The ZVS and ZVDS conditions could also be satisfied in the class EF family amplifiers.

In comparison with the mentioned structures, the class $\mathrm{E}$ PA has high drain efficiency; however, its $C_{p}$ factor is low. Therefore, increasing the $C_{p}$ factor and decreasing the voltage stress in class $\mathrm{E}$ amplifier, are still subject to interest. In this paper, a harmonic control network $(\mathrm{HCN})$ is designed and applied in the typical class $\mathrm{E}$ amplifier circuit to reduce the maximum value of the MOSFET voltage and also to improve the $C_{p}$ factor of the amplifier.

The paper sections are summarized as follows. Sections II and III present the structure and specifications of the typical class E PA. Description of the presented $\mathrm{HCN}$ and $C_{p}$ factor of the presented PA are described in Sections IV and V, respectively. Obtained results of the design examples are given in Section VI. Finally, the conclusions of the obtained results are presented in Section VII.

\section{TyPICAL Class E PA StRUCTURE}

The typical class E circuit is depicted Figure 1, which includes a transistor (MOSFET) as a switch, RF choke, series resonator, dc supply voltage $\left(V_{d c}\right)$, and a parallel capacitance. The parallel capacitance $\left(C_{s h}\right)$ in class E PA includes the MOSFET intrinsic capacitance $\left(C_{d s}\right)$ and a shunt external capacitance. However, the external capacitance could be neglected to reach higher operating frequency. 


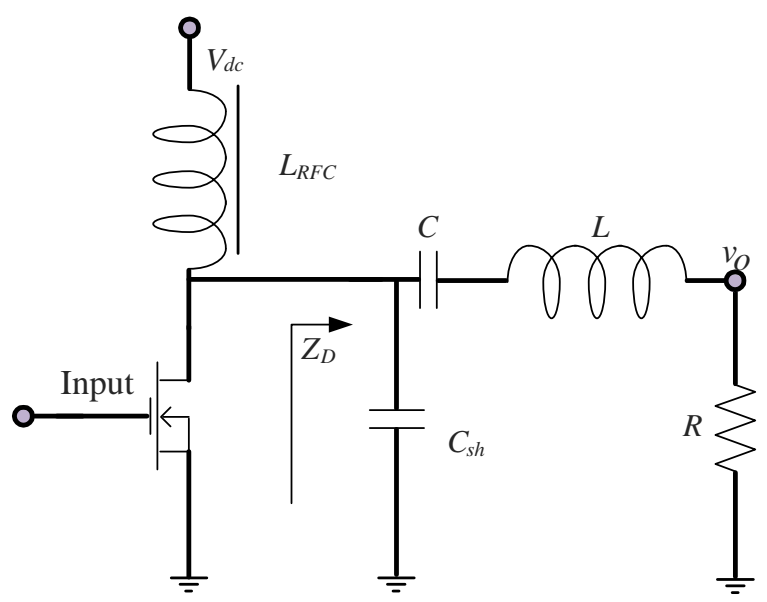

Fig. 1. Typical class E circuit

The normalized MOSFET voltage $\left(v_{s} / V_{d c}\right)$ and normalized MOSFET current $\left(i_{s} / I_{d c}\right)$ waveforms of a typical class $\mathrm{E}$ structure are illustrated in Fig. 2. According to this figure, the maximum values of $v_{s} / V_{d c}$ and $i_{s} / I_{d c}$ for typical class $\mathrm{E}$ amplifier are 3.56 and 2.86, respectively. According to breakdown voltage constraints of the MOSFET, $V_{d c}$ and subsequently the output power could not exceed from a specific value and this problem limits the design procedure. With reduced maximum switch voltage, more output power could be achieved, and the design process of the presented structure would be more flexible.

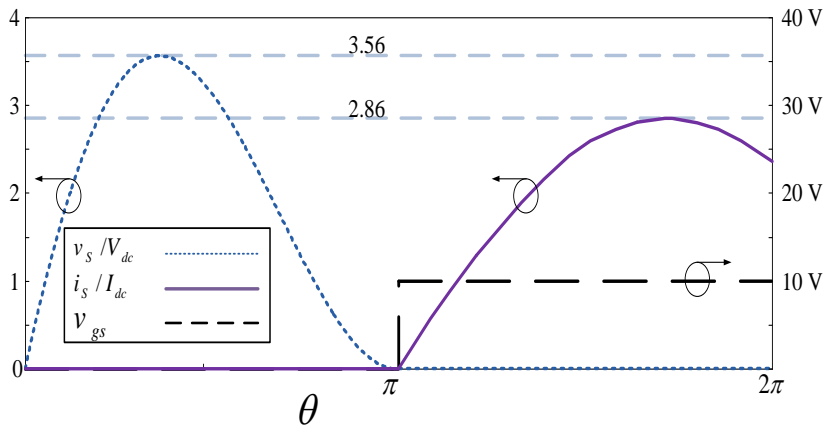

Fig. 2. $v_{s} / V_{d c}$ and $i_{s} / I_{d c}$ waveforms of the typical class $E$ structure

\section{DRAIN IMPEDANCE}

In class E structure, the MOSFET plays the switch role in the circuit and threshold voltage $\left(V_{t h}\right)$ acts as a trigger for this switch. It means when the input voltage value is higher than $V_{t h}$, the switch (MOSFET) is on, and the value of $v_{s}$ is equal to zero. On the contrary, when the input voltage value is lower than $V_{t h}$, the switch (MOSFET) is off, and the switch voltage can be calculated, according to the amplifier circuit. The obtained switch voltage waveform of class $E$ amplifier depends on the drain impedance $\left(Z_{D}\right)$. According to Fig. 1 , the value of $Z_{D}$, can be calculated as follows

$$
Z_{D}=\frac{L C S^{2}+R C S+1}{L C C_{s h} S^{3}+R C C_{s h} S^{2}+\left(C+C_{s h}\right) S} .
$$

As can be seen in equation (1), the value of $Z_{D}$ is a function of $L, C, C_{s h}, R$, loaded quality factor $(Q)$ and frequency. From equation (1), the value of $Z_{D}$ for the typical class E PA output structure could be achieved, which is depicted in Fig. 3. The drain impedance of the typical structure has a zero and a pole near the operating frequency.
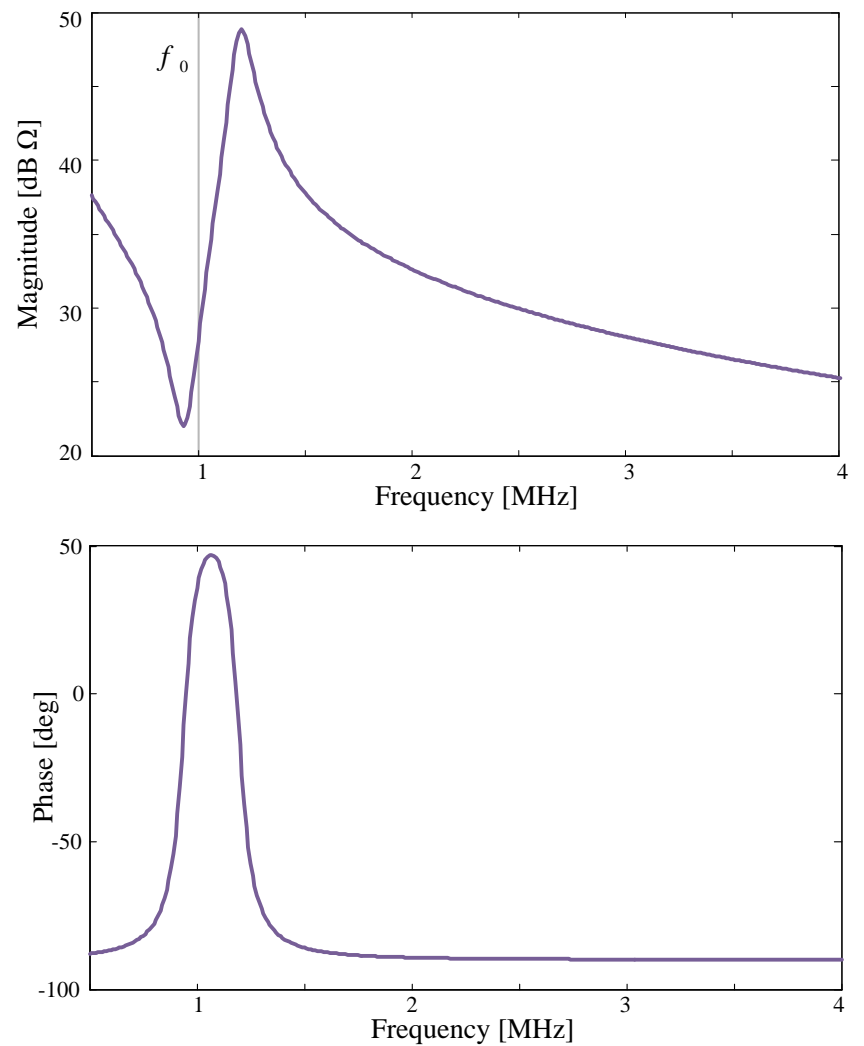

Fig. 3. The value of $Z_{D}$ for the typical class $E$ output structure

In the circuit structure, high value of $Q$ for the resonant circuit provides a pure sinusoidal voltage at $v_{o}$. The value of loaded quality factor could be written as

$$
Q=\frac{\omega L}{R},
$$

where $\omega$ is angular frequency. Effect of different values of $Q$ on drain impedance is shown in Fig. 4. According to this figure, as the loaded quality factor increases, the zero and pole of the impedance become closer to operating frequency, and the ideal resonator will be achieved with a high value of $Q$.

\section{HARMONIC CONTROL NETWORK}

As mentioned, the class E PA drain voltage depends on the drain impedance. It means the switch voltage can be reduced using harmonic control elements. A harmonic control network is designed and inserted in typical class $\mathrm{E}$ circuit to decrease the MOSFET voltage. The proposed HCN structure includes two resonator branches, as illustrated in Fig. 5. The circuit values of the designed circuit are tabulated in Table 1. 

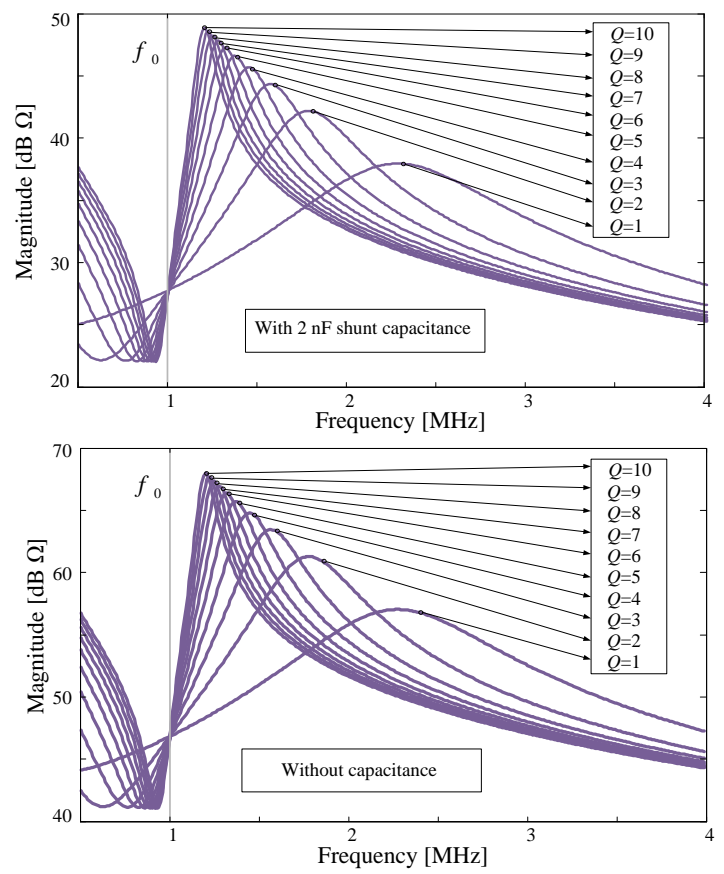

Fig. 4. Effect of $Q$ on the typical class E PA drain impedance with and without shunt capacitance

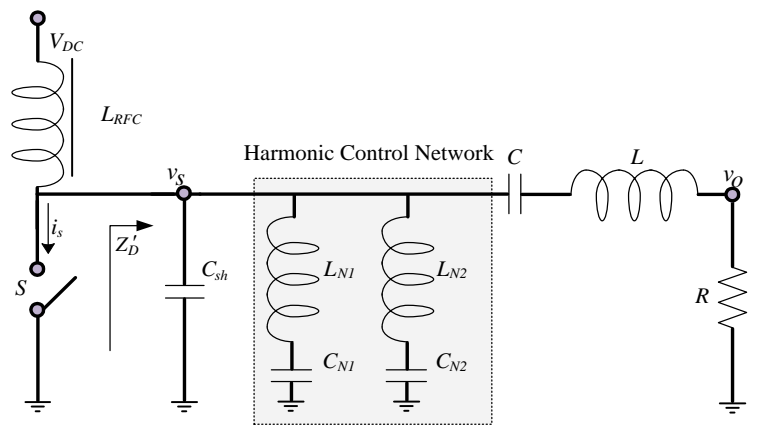

Fig. 5. Proposed harmonic control network in the amplifier circuit

The impedance of the HCN could be written as

$$
Z_{H C N}=\frac{L_{N 1} L_{N 2} C_{N 1} C_{N 2} S^{4}+\left(L_{N 1} C_{N 1}+L_{N 2} C_{N 2}\right) S^{2}+1}{C_{N 1} C_{N 2}\left(L_{N 1}+L_{N 2}\right) S^{3}+\left(C_{N 1}+C_{N 2}\right) S} .
$$

The impedance of the $\mathrm{HCN}$ is illustrated in Fig. 6. There is a zero in the impedance of the presented $\mathrm{HCN}$ in the third harmonic of the operating frequency. According to Fig. 5, the drain impedance of the proposed amplifier is

$$
Z_{D}^{\prime}=Z_{H C N} \frac{L C S^{2}+R C S+1}{F(S)}
$$

where $F(S)$ is defined as

$$
\begin{aligned}
F(S)= & Z_{H C N} L C C_{s h} S^{3}+\left(L C+Z_{H C N} R C C_{s h}\right) S^{2} \\
& +\left(Z_{H C N}\left(C+C_{s h}\right)+R C\right) S+1
\end{aligned}
$$
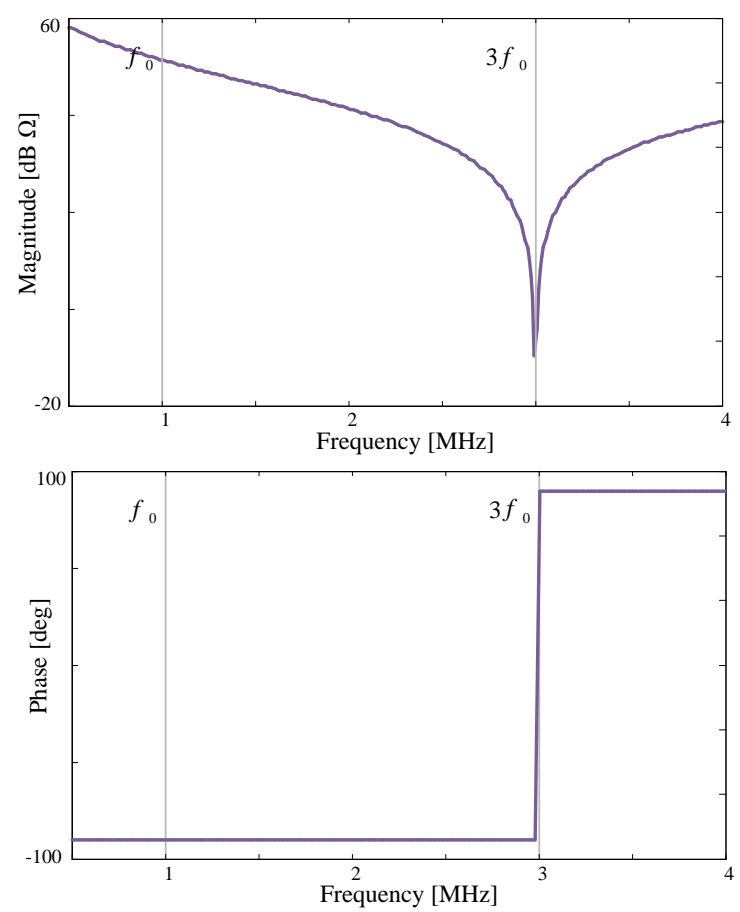

Fig. 6. Impedance of the presented $\mathrm{HCN}$
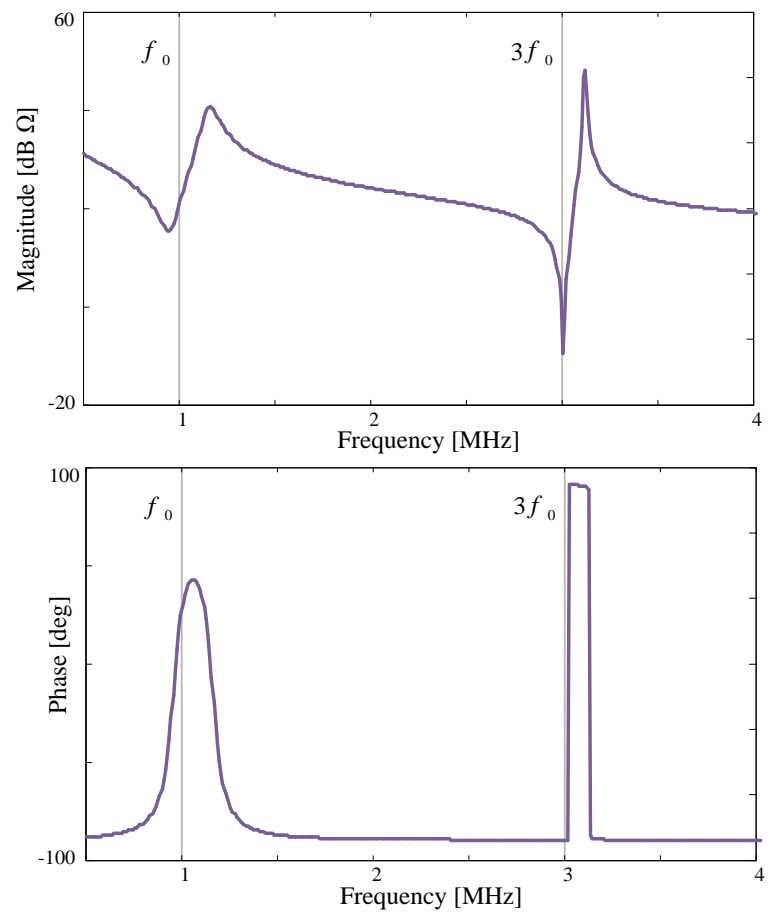

Fig. 7. Drain impedance of the presented amplifier using the proposed $\mathrm{HCN}$

The drain impedance of the presented amplifier using the proposed HCN is shown in Fig. 7.

\section{OUTPUT POWER CAPABILITY}

To compare the output power of different amplifiers, the output power capability $\left(c_{P}\right)$ factor is used. The $c_{P}$ factor could be calculated as follows [20] 


$$
c_{P}=\frac{P_{o, \max }}{v_{s, \max } i_{s, \max }}=\frac{1}{\frac{v_{s, \max }}{V_{D C}} \frac{i_{s, \max }}{I_{D C}}}
$$

As can be concluded from (6), the value of $c_{P}$ is proportional to inverse values of $v_{s, \max } / V_{d c}$ and $i_{s, \max } / I_{d c}$. The value of $c_{P}$ can be calculated for the typical class E PA, according to values of $v_{s, \max } / V_{d c}$ and $i_{s, \max } / I_{d c}$, which is 0.098 .

\section{Simulation Results AND DESIGN EXAMPLES}

The presented amplifier is simulated at $1 \mathrm{MHz}$, using ADS and PSpice software. An IRF530 MOSFET transistor is applied as a switch in the designed class $E$ circuit. The first design example is simulated using ADS software. A switch model with relevant parasitic elements is used in the ADS simulation to model the switching device. The MOSFET on resistance $\left(\mathrm{R}_{\mathrm{DS}(\mathrm{on})}=0.16 \Omega\right)$ is considered, according to the IRF530 MOSFET datasheet. To validate the ADS simulation results, the second design example is simulated using PSpice software. The circuit values and design parameters of two design examples are the same, except the load resistance. The small difference in the load resistance is due to the MOSFET parasitic elements, which were considered in the PSpice simulation. Parasitic resistances and capacitances of the MOSFET are considered in the PSpice model. The IRF530 level 3 PSpice model is used in this paper. Simulated results of the first and second design examples are shown in Fig. 8 and Table 2. According to the PSpice simulation results, the normalized maximum MOSFET voltage and MOSFET current of the presented PA have been achieved 2.76 and 2.95, respectively. Subsequently, from equation (6), the $c_{P}$ factor for the presented PA can be obtained as 0.122 . The $c_{P}$ factors of different amplifiers are compared in Table 3. According to the results, the presented $\mathrm{HCN}$ can improve both the $c_{P}$ factor and the MOSFET voltage. More parameters of class $\mathrm{E}$ amplifier could be improved using a modified $\mathrm{HCN}$, which we will address in future work. As mentioned, the drain impedance shapes the MOSFET voltage and currents of the amplifier. Therefore, several limitations of class E PA could be removed using a modified $\mathrm{HCN}$.

TABLE I. Circuit VALUes of Designed AMPLIFIER

\begin{tabular}{cc}
\hline $\boldsymbol{V}_{\boldsymbol{D C}}$ & $\mathbf{1 2 ~ V}$ \\
\hline$f_{0}$ & $1 \mathrm{MHz}$ \\
\hline$L$ & $11 \mu \mathrm{H}$ \\
\hline$C$ & $2.53 \mathrm{nF}$ \\
\hline$C_{s h}$ & $5 \mathrm{nF}$ \\
\hline$L_{N 1}$ & $7.8 \mu \mathrm{H}$ \\
\hline$C_{N 1}$ & $360 \mathrm{pF}$ \\
\hline$L_{N 2}$ & $10 \mu \mathrm{H}$ \\
\hline$C_{N 2}$ & $10 \mathrm{pF}$ \\
\hline
\end{tabular}

TABLE II. DESIGN EXAMPLES RESULTS

\begin{tabular}{ccc}
\hline & $\begin{array}{c}\text { First design } \\
\text { example }\end{array}$ & $\begin{array}{c}\text { Second design } \\
\text { example }\end{array}$ \\
\hline$V_{\text {in }}$ & $10 \mathrm{~V}$ & $10 \mathrm{~V}$ \\
\hline$R$ & $5.8 \Omega$ & $6.2 \Omega$ \\
\hline$v_{s, \max }$ & $33.12 \mathrm{~V}$ & $33.4 \mathrm{~V}$ \\
\hline$V_{o}$ & $11.8 \mathrm{~V}$ & $12.3 \mathrm{~V}$
\end{tabular}

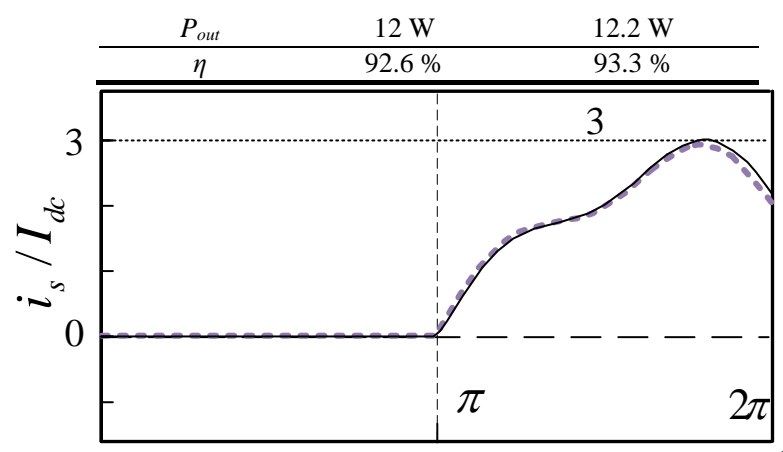

$\theta$
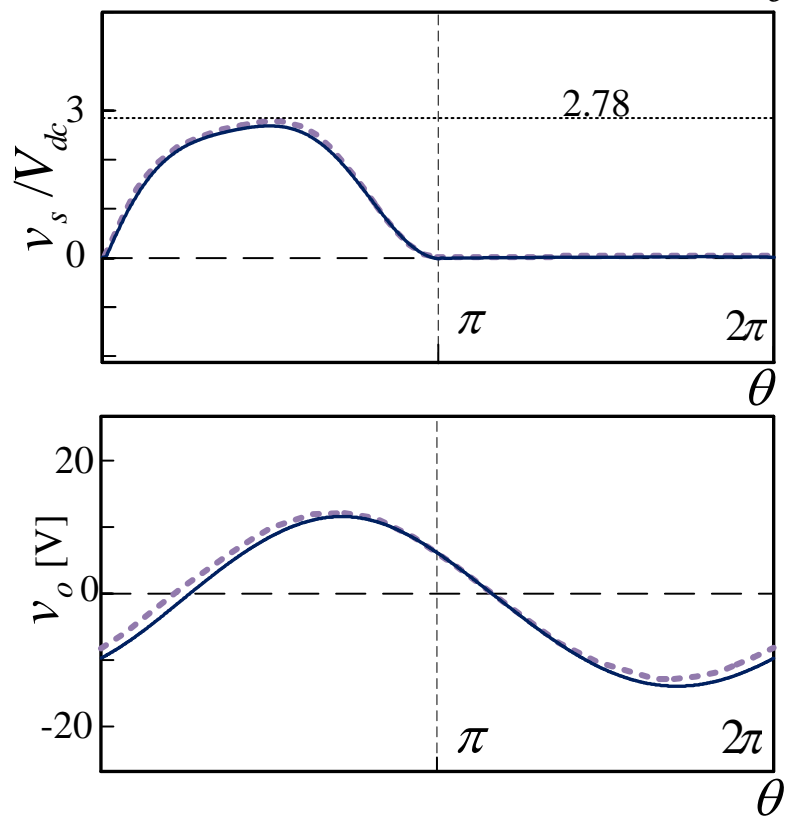

Fig. 8. Simulated waveforms of the presented amplifier using ADS (dashed line) and PSpice (solid line)

TABLE III. OUtPut Power CAPABILITIES $\left(C_{P}\right)$ OF DifFERENT AMPLIFIERS

\begin{tabular}{cc}
\hline Amplifier Type & $\boldsymbol{c}_{\boldsymbol{P}}$ \\
\hline Class B & 0.125 \\
\hline Class D & 0.159 \\
\hline Class E & 0.098 \\
\hline Class DE & 0.079 \\
\hline This work & $\mathbf{0 . 1 2 2}$ \\
\hline
\end{tabular}

\section{CONCLUSION}

A new harmonic control network $(\mathrm{HCN})$ is inserted in typical class E power amplifier structure. According to the results, several parameters of class E PA are improved, using the applied HCN. The voltage stress of the presented amplifier is reduced, which relaxes the design limitations of the presented PA. Besides, the output power capability is increased, when compared with the other amplifiers. According to the results, the proposed amplifier structure presents both high-efficiency advantage of class E PA and high output power capability advantage of class D PA.

\section{REFERENCES}

[1] A. Banerjee, L. Ding, and R. Hezar, "High efficiency multi-mode outphasing RF power amplifier in 45nm CMOS" In European Solid- 
State Circuits Conference (ESSCIRC), ESSCIRC 2015-41, pp. 168-171, 2015.

[2] M. Hayati, S. Roshani, M. K. Kazimierczuk, and H. Sekiya, "A class E power amplifier design considering MOSFET nonlinear drain-to-source and nonlinear gate-to-drain capacitances at any grading coefficient," IEEE Transactions on Power Electronics, 2016, to be published, DOI: 10.1109/TPEL.2015.2512928.

[3] M. Hayati and S. Roshani, "A Class E Power Amplifier with Low Voltage Stress," Amirkabir International Journal of Electrical \& Electronics Engineering, 47(1), pp. 31-37, 2015.

[4] M. Hayati, S. Roshani, M. K. Kazimierczuk, and H. Sekiya, "Analysis and Design of Class E Power Amplifier Considering MOSFET Parasitic Input and Output Capacitances," IET Circuits, Devices \& Systems, 2016, to be published, DOI: 10.1049/iet-cds.2015.0271.

[5] K. Pengand and E. Santi, "Class E resonant inverter optimized design for high frequency $(\mathrm{MHz})$ operation using eGaN HEMTs," In Applied Power Electronics Conference and Exposition (APEC), pp. 2469-2473, 2015

[6] S.C. Wong and C.K. Tse, "Design of symmetrical class E power amplifiers for very low harmonic-content applications," IEEE Transactions on Circuits and Systems I: Regular Papers, 52(8), pp.16841690, 2005.

[7] C. Chan and C. Toumazou, "Physically based design of a class e power amplifier with non-linear transistor output capacitance," In COLLOQUIUM DIGEST-IEE, pp. 5-5 1999.

[8] N. Ha-Van, N. Dang-Duy, H. Kim, and C. Seo, "Frequency limitation of an optimum performance class-E power amplifier," IEICE Electronics Express, 2016, to be published, DOI: 10.1587/elex.13.20160108.

[9] Y. Yusop, M.S.M. Saat, S.H. Husin, S.K. Nguang, and I. Hindustan, "Design and Analysis of $1 \mathrm{MHz}$ Class-E Power Amplifier for Load and Duty Cycle Variations," International Journal of Power Electronics and Drive Systems (IJPEDS), 7(2), 2016.

[10] A. Mediano, P. Molina-Gaudo, and C. Bernal, "Design of class E amplifier with nonlinear and linear shunt capacitances for any duty cycle," IEEE Transactions on Microwave Theory and Techniques, 55(3), pp. 484-492, 2007.

[11] X. Du, J. Nan, W. Chen, and Z. Shao, "New solutions of Class-E power amplifier with finite dc feed inductor at any duty ratio," IET Circuits, Devices \& Systems, 8(4), pp. 311-321, 2014.

[12] T. Mury and V. F. Fusco, "Sensitivity characteristics of inverse Class-E power amplifier," IEEE Transactions on Circuits and Systems I: Regular Papers, 54(4), pp. 768-778, 2007.

[13] S.H. Kam, O.S. Kwon, M.W. Lee, and Y.H. Jeong, "High-efficiency inverse class-E power amplifier with envelope tracking technique," Microwave and Optical Technology Letters, 55(4), pp.866-869, 2013.

[14] T. Cao, Y.J. Liu, R. Zeng, and L.M. LV, "S-band high efficiency GaN inverse-class E power amplifier," J Microw, 27(4), pp.49-52, 2011.

[15] G. Formicone and J. Custer, "Mixed-mode class EF- 1 high efficiency $\mathrm{GaN}$ power amplifier for P-band space applications" In Microwave Symposium (IMS), IEEE MTT-S International, pp. 1-4, 2015.

[16] S. Aldhaher, D. C. Yates, and P. D. Mitcheson, "Modeling and Analysis of Class EF and Class E/F Inverters With Series-Tuned Resonant Networks," IEEE Transactions on Power Electronics, 31(5), pp. 34153430, 2016.

[17] M. Thian, A. Barakat, and V. Fusco, "High-efficiency harmonic-peaking Class-EF power amplifiers with enhanced maximum operating frequency," IEEE Transactions on Microwave Theory and Techniques, 63(2), pp. 659-671, 2015.

[18] T. Kondo, and H. Koizumi, "Class DE voltage-source parallel resonant inverter," In Industrial Electronics Society, IECON 2015-41st Annual Conference of the IEEE pp. 002968-002973, 2015.

[19] H. Sekiya, X. Wei, T. Nagashima, and M. K. Kazimierczuk, "SteadyState Analysis and Design of Class-DE Inverter at Any Duty Ratio," IEEE Transactions on Power Electronics, 30(7), pp. 3685-3694, 2015.

[20] M. J. Chudobiak, "The use of parasitic nonlinear capacitors in class-E amplifiers," IEEE Transactions on Circuits and Systems I, 41(12), pp. 941-944, 1994. 